\title{
1007 TRADES APPRENTICE SAFETY TEAM CHALLENGE
}

New Plymouth injury Safe Trust in partnership with the Taranaki Construction Safety Focus Group Correspondence to New Plymouth injury Safe, c/- Public Health, Taranaki DHB, Private Bag 2016, New Plymouth 4342, New Zealand

10.1136/ip.2010.029215.1007

The film provides an overview of an annual practical safety competition - the Taranaki Trades Apprentice Challenge aimed at construction trades apprentices in Taranaki. It includes 
film of the competition in progress, along with interviews with those organising and running the 'challenge' activities on the day. The Taranaki Construction Safety Focus Group organise the annual event which consists of a practical and interactive competition designed to test the safety knowledge and skills of apprentices aged 18-25 years from local trades and construction industries. The practical challenges each last $20 \mathrm{~min}$ and focus on safety topics such as working at heights, road safety, fire safety, manual handling, home safety, personal safety, physical fitness and first aid. The activities are run by representatives from local safety groups and construction companies. Winners receive a Master Builders sponsored Apprentice Safety Trophy. The first competition was held in 2009 and was won by Shell Todd Oil Services and then in 2010 by Tenix. What is particularly interesting about this event is that it is not the only one of its kind in Taranaki! The authors also host a long running agricultural challenge event (ATV driving, tractor driving, cattle handling etc) held on a working farm (aimed at agricultural students), a Gateway Safety Challenge (aimed at gateway trades students aged 15-16) and, most recently, a Business House Safety Challenge aimed at local businesses with a focus on the links between home, road and workplace safety. While the competition appears to be just that, it is increasingly being recognised by local industry as a powerful and effective learning tool for young people in particular. The Trades Apprentice Challenge has now been replicated in other parts of New Zealand and there are plans to incorporate the competition into the Registered Master Builders Apprentice of the Year competition. 